\title{
Diretrizes Para Colonizações no Brasil
}

\author{
José de Almeida Rios \\ Diretor da Seção de Segurança Nacional \\ do Ministério da Educação e Cultura
}

Considerações gerais:

\section{A}

s características de como se processaram as colonizações no século passado e nas primeiras décadas dêste sofreram profundas modificações. Estas são conseqüências de dois fatôres marcantes: a industrialização e conseqüente urbanização e a evolução extraordinária dos meios de transportes e comunicações. As duas primeiras recebendo mais diretamente a influência da Tecnologia, dadas as responsabilidades mais imediatas e seguras de rentabilidade, puderam com mais rapidez dispensar ao individuo os favores do bem-estar assim como conseguir para o grupo urbano melhores possibilidades de assistência. A maior aglomeração humana na evolução dos direitos políticos teve melhor quinhão na distribuição de rendas, dado que agia em função de sua atividade civica justamente quando foram estabelecidos pelos Congressos os postulados dos direitos do homem.

O homem do campc, que nos tempos idos estabelecia a sua maneira de viver dentro do circulo comunal e familiar, desinteressando-se pela politica e pelos Organismos Políticos Centralizados, começou a ter conhecimento rápido e constante da forma de viver, de viver e de sentir dos homens politizados dos centros urbanos, com a evolução dos transportes e comunicações. A difusão cultural tomou vulto e levou ao campo o conhecimento dos direitos de seus habitantes, além da importância que cabe às atividades sociais na conservação do bem-estar urbano. Assim, a par das reivindicações sociais das massas urbanas seguiram-se aquelas dos agricultores.

$\mathrm{Na}$ Europa de hoje a assistência social é abundantemente dispensada ao homem do campo. Por outro lado, a Tecnologia levada ao campo permitiu maior produtividade ao trabalhador agrícola, dando ensejo a que o Capital realmente preenchesse a 
sua elevada função social. As guerras e invasões dos séculos anteriores destruiam tudo na sua passagem e exigiam reparações quase individuais atingindo exatamente a economia particular. Dentro de tal quadro só restaria a procura de novos sítios de localização. Nas levas sucessivas de imigrantes que procuravam - Nôvo Mundo vieram muitos falsos agricultores e nada mais eram do que artesãos formados através de várias gerações. No Brasil, por exemplo, tais elementos, quando se ampliavam os núcleos sociais dos grupos imigrados, abandonavam as lides agrícolas e entregavam-se vantajosamente às suas verdadeiras habilitações. O surto industrial do Estado do Rio Grande do Sul e São Paulo teve origem, em boa parte, em tal fato.

Por outro lado e por motivo ainda do progresso das comunicações e transportes, a difusão cultural atingiu especialmente os homens do campo. Assim, dentro de tal raciocínio, muito dificilmente e a não ser em condições bem favorecidas, o excedente das populações campesinas dos países de imigração, tais como a Itália, Portugal e Espanha, se encaminhará a paises receptores. Por outro lado, o primeiro tem melhorado razoàvelmente a vida de sua região sul que se mantinha até há pouco em nivel bastante deficiente. O segundo está procurando desenvolver as suas colônias da Árica. O terceiro tem introduzido elementos novos de trabalho no aproveitamento de suas terras que eram exploradas deficiente e inadequadamente.

No Brasil poderemos ainda com vantagem conseguir pequenos e limitados núcleos de agricultores para trabalharem em conjunto com núcleos bem maiores de elementos nacionais em Colonizações perfeitamente enquadradas nas condições favoráveis ao "status social" do século.

Certas iniciativas de grupos imigratórios oriundos de paises com nivel cultural bem mais elevado do que a média de nosso meio rural, não constituem pròpriamente uma Colonização e sim uma "transferência". Grupos holandeses, com capital e tecnologia evoluída, aliados a um bom nivel educacional, transferem-se para o Brasil e vendem seus produtos ao mesmo país. Dado o grande desnivel cultural não se estabelece a "sincretização", justamente o processo de aculturação. Um pequeno desnivel favorece a assimilação. Assim sendo, sòmente a localização de um núcleo estrangeiro de elevado nivel cultural próximo a um meio social adequado, é que poderá permitir a assimilação e a aculturação, elementos subjetivos essenciais de uma imigração. Hoje geralmente as populações campesinas brasileiras, argentinas e uruguaias apresentam uma situação cultural igual e mesmo mais elevada do que regiões de alguns países europeus de imigração. 
Sob o ponto-de-vista útil ao Brasil, isto é, o sentido subjetivo de "aculturação", nada vemos que nos aconselhe a imigração de tal qualidade.

Assim, pois, nas Colonizações a serem planejadas, sòmente elementos mais selecionados deverão ser encaminhados ao nosso pais. A mesma assistência tecnológica deverá ser dispensada tanto ao elemento estrangeiro quanto ao colono nacional.

Encontramos na imigração japonêsa uma das mais importantes questões a serem estudadas. O surto industrial do Japão já não suporta a absorção do seu excesso de população e o elevado nivel tecnológico no meio rural já não consegue, pela exigüidade de terras agricultáveis, o aproveitamento e acomodação para seu tremendo surto demográfico. Existe sòmente a solução na imigração. A sobriedade, o amor ao trabalho, o elevado nivel cultural, a inclinação à poupança, a determinação de cumprimento da lei, tem tornado o japonês indesejável aos países do Oriente. Onde quer que se localize, progride, absorve e evolui. As aten. ções do Govêrno Japonês estão inteiramente voltadas para nossi) pais. Ainda não temos elementos seguros para compreender como e em que condições poderá ser útil a nosso país a imigração japonêsa. Como frisamos, o elemento essencial em uma imigração é a aculturação e o caminho mais seguro é a assimilação biológica. Esta tem sido bastante retardada. No meio urbano o processo é mais acelerado pelo fato de que aí existe maior concentração de segunda geração em fase social de assimilação. No campo, porém, o problema é diferente e mais difícil. Acreditamos que Colonizações mistas e de condições favoráveis poderão acelerar o processo. Conseguido isso, tornar-se-á o elemento japonês excelente meio de elevação do meio cultural rural de nosso pais.

Em linhas gerais, uma Colonização deve constituir uma "semente" social, higida e integral, sob o ponto de vista mental e físico. Não poderemos educar, no sentido de "ensinar a viver bem", sem os requisitos correspondentes. Para isso é preciso produzir bem e dispor dos recursos correspondentes. Não se pode educar hoje sem os meios apropriados de divulgação. Sem a eletricidade doméstica não será possivel educar uma população campesina dispersa. Por outro lado, a energia irá propiciar o ensinamento da indústria doméstica e artesanato rural, fontes iniciais de industrialização e de segurança no aproveitamento dos excedentes de cultivo, assim como de utilização dos meios de informações tão necessários à integração do cidadão. Por outro ângulo, a atividade cíclica da lavoura dispensa ao agricultor e à sua familia, a oportunidade de aproveitar no seio familiar as horas forçadamente livres. A eletricidade e a água domiciliares ensejarão a prática dos mais sãos princípios de vivência, máxime, quanto 
à higiene, dentro dos quais viverão as futuras gerações. A deformidade na maneira de viver nos obrigará mais tarde a grandes inversões na recuperação educacional de várias gerações. Por outro lado, não sendo dado ao campo um mínimo de condições de bem-estar e de produtividade, através das comunicações fáceis terá conhecimento de que a sua vida do campo é de fato uma alternativa. Emigrará para a região urbana logo que a oportunidade se apresente. As atrações da cidade, o confôrto, a assistência social, os divertimentos, os meios educacionais mais favoráveis etc., decidirão de sua resolução.

Além disso, a Colonização estabelecida em condições apropriadas ao sistema de vida do Século nada mais representa do que um núcleo sócio-econômico, estável e definitivo, funcionando como centro de ampla divulgação cultural (o que denominamos processo germinativo, social e econômico). Este é realmente o aspecto mais importante das colonizações sob o ponto-de vista que passamos a expor.

\section{II}

\section{OBJETIVOS DE UM PLANO DE COLONIZAÇÃO RACIONALIZADA PARA O BRASIL}

1. Ocupar os espaços vazios como método fundamental de uma Politica de Segurança Nacional; nômicas;

2. Diminuir os desniveis entre as diversas regióes geo-eco-

3. Estabelecer núcleos de irradiação para elevação cultural do meio rural e atuação germinativa no sentido sócio-econômico;

4. Fixar bases estruturais econômicas definitivas para as vias de comunicações pioneiras e estradas de ferro deficitárias; solo;

5. Divulgar métodos agrícolas racionais e de conservação de

6. Corrigir deformidades existentes nas caracteristicas do trabalho agricola e da posse da terra;

7. Conseguir o reajustamento dos desequilibrios demográficos e do tamanho antieconômico das propriedades agricolas; rural;

8. Facilitar a assistência educacional e tecnológica no meio

9. Diversificar a produção agrícola, especialmente quanto a gêneros alimentícios, aumentando a produção em regiões de superconsumo;

10. Concorrer para a mais fácil assimilação de núcleos estrangeiros de imigração; 
11. Aproveitar as terras potencialmente valorizadas e com produção deficiente ou inadequada;

12. Concorrer para formação cooperativista ou coletiva de trabalho agrícola, libertando o produtor do contrôle monopolista do beneficiamento industrial.

13. Concretizar uma política de formação da média propriedade e da exploração mista agropecuária, assim como uniformização da superficie dos lotes, visando facilitar o trabalho e o escoamento da produção;

14. Instalar novas unidades politicas municipais, fundamen tadas em favoráveis estruturas sócio-econômicas;

15. Procurar os novos rumos educacionais objetivos, associando à Escola a Oficina e o Trabalho nos núcleos sócio-educativos e, através do setor de Coordenação, com as Entidades Oficiais e Privadas de ocupação profissional, corrigindo assim, dois fatôres negativos da conjuntura brasileira: o abandono da Escola por motivos especialmente econômicos e o elevado indice demográfico de pessoas jovens. Do mesmo modo, a revelação vocacional espontânea sem influências emotivas ou sociais, eliminando assim os inconvenientes e as dificuldades da seleção vocacional.

\section{III}

CARACTERÍSTICA DE COLONIZAÇÃO SEGUNDO CONDIÇõES POLÍTICAS, GEOGRÁFICAS E SOCIAIS LOCAIS

Para estabelecer a Política de consecução dos objetivos haverá necessidade de pesquisar a situação local e regional. Os meios são sempre variáveis a um fim estabelecido, conforme as condições locais e regionais a serem investigadas e dados analisados. Evidentemente um país de extensão continental, com imensa área de dependência marítima, com zonas culturais dispares dentro do mesmo Estado, sujeito a faixa de limites com o estrangeiro das maiores do mundo, possuindo os mais variados matizes de evolução politica e de garantias individuais, populações esparsas com niveis mentais variados, não comportaria um mesmo procedimento para atingir um fim visado. Contudo, reconhecendo a necessidade de estabelecer as linhas mestras de uma Colonização, fôrça é convir que certas particularidades locais e regionais nos levarão a aconselhar meios e métodos diferentes para cada caso. Enquadra-se isso na semântica do têrmo Planejamento que é prever e prover.

Por outro lado, considerando-se o desenvolvimento econômico no set1 processo natural obedecendo a leis mais ou menos 
uniformes e sujeita a ciclos negativos naturais, haverá necessidade de enquadrar as iniciativas artificiais de desenvolvimento dentro das condições globais de evolução econômica. O Brasil, na sua excepcional mobilidade sócio-econômica, dispondo de uma imensa gama de iniciativas pioneiras de fundo econômico e alta rentabilidade de Capital, sujeita-nos a meditação de que se valeria a pena inverter em atividades primárias os capitais necessários em outros setores de mais sugestiva renda "per capita" e recuperação a prazos bem mais curtos.

Contudo, a História nos ensina que o desenvolvimento econômico baseado na industrialização não se pode fazer de forma "introvertida". E' preciso existir um meio de adquirir de outros paises os bens de produção, equipamentos, técnica e mesmo matéria-prima. Por outro lado, quanto mais se industrializa um pais mais necessita importar matérias-primas e outros bens de consumo, inclusive alimentares. Nesta fase, porém, tendo o desenvolvimento obedecido à evolução econômica natural ou suficientemente estimulado e de modo favorável, já a capacidade de importar fundamenta-se no produto acabado e dentro dos preços competitivos internacionais. Tais trocas" ainda serão mais favoráveis quando o volume de matérias-primas utilizadas provêm do próprio território. E' justamente neste ponto que a Colonização poderá lançar a semente decisiva, máxime, em um território continental como o nosso, em que uma parte minima do solo possui o seu inventário. Esta deverá ser uma das ações iniciais, a previsão da escolha de um sítio para instalação de um núcleo sócioeconômico. A elevação de nivel de vida, em prazo relativamente curto, de uma população que se mantinha em condições deploráveis de consumo, trouxe um argumento enganador no que se refere à instalação de indústrias de transformação, relegando a segundo plano o interêsse pela produtividade e pelo problema de custo. Esgotado o campo consumidor interno, realmente muito limitado e pequeno em relação ao volume demográfico, teremos que lançar mão de mercado internacional a cuja preço competitivo não conseguiremos concorrer. Isto se dá justamente porque a conjuntura brasileira distorceu a evolução natural do surto industrial. Via de regra, não passou êle pela fase artesanal. Neste ponto, a Colonização bem orientada poderá corrigir parcialmente.

A economia politica não é simplesmente a ciência da riqueza, mas sim o instrumento que estabelece relações entre ela $e$ o bemestar do homem. Infelizmente a objetividade e o imediatismo acompanha o homem na sua fase incipiente de cultura rolitica. Dai decorre justamente o imperativismo de colocar em plano mais elevado o fundamento educacional, alicerce inconteste da providência, qualidade indispensável ao homem de govêrno. Advo 
gando prioridade para os princípios subjetivos nas Colonizações, não poderemos deixar de citar lideres do pensamento nas suas explosões orientadoras visando os fundamentos básicos de. uma civilização. RENÉ HuBER, ilustre educador francês em sua obra Histoire de la Pedagogie diz:

"Como no tempo de Platão, como no Século da Renascença, como na época de Rousseau, o problema da educação é todo o problema do homem, do seu destino na natureza, do seu destino na sociedade, do seu destino segundo o Espirito".

Deve, pois, preocupar ao planejador os assuntos educacionais quando pretender a curto e a longo prazo estruturar os meios produtores de homens visando sempre os interêsses e conveniências da coletividade.

A civilização trouxe ao solo outras responsabilidades de cujo conhecimento o homem tem necessidades de integrar-se; a quebra do ciclo biológico da natureza depõe nos ombros da civilização atual a responsabilidade de resguardar a vitalidade do solo. "Cada Estado é um pedaço de chão. Sem solo não chegamos a imaginar o homem nem tampouco sua obra-prima sôbre a terra: o Estado ....... O Estado tem de viver do solo", disse Ratzel.

Imaginando as Civilizações extintas ou desconhecidas. GiFFORD PINCHOT em Better Living through vise use of Resourches replica espetacularmente:

“Uma Nação privada da liberdade pode readquiri-la, uma Nação dividida pode unificar-se, mas uma Nação cujos recursos foram destruídos pagará inevitàvelmente com a pobreza, a degradação e a decadência".

Assim, uma prática agricola racional e uma consciência do problema 'lorestal tornarão mínimos os desgastes e o impacto que a Civilização traz ao solo. Para que o homem haja e atue nos bons principios educacionais necessita êle certas e determinadas prerrogativas e vantagens. A saúde constitui um bem a que o homem tem direito $\mathrm{e}$ a sociedade não pode furtar-se de propiciá-la. Em obra Brasil, and Expanding Economy, George WYTH diz:

"A saúde é indubitàvelmente um dos maiores problemas do Brasil de hoje, sendo que em nenhum outro terreno podem tão grandes lucros ser obtidos com investimento relativamente tão pequeno". 
As novas fontes de energia aliadas à higiene e a medicina deram ao homem elementos novos do bem-estar, conseguindo para êle condições mais favoráveis para a conquista de bens materiais em maior quantidade possibilitando o acesso ao maior número. A saúde e a higiene tem apressado sobremodo a demografia mun. dial e as novas fontes energéticas deram ao homem uma energia passando de 4.000 para 160.000 calorias. Eis porque a economia política ao planejar a constituição de um núcleo sócio-econômico hígido terá que prever e prover as necessidades do homem na sua faina de nutrir a seus semelhantes, alimentar a indústria e causar ao solo o mínimo de desgaste.

Parece-nos assim ter defendido para as Colonizações brasileiras as aquisições fundamentais para a criação de núcleos sociais, higidos, mental e fisicamente.

\section{IV}

\section{ALGUMAS CONDIÇÕES ESPECIAIS EXISTENTES NA CONJUNTURA} NACIONAL E OS PROCESSOS COLONIZADORES ADEQUADOS

I - A região do nordeste conhecida por "zona da mata" é prêsa de um excedente populacional que vive nas piores condições e tradicionalmente encontra-se enraizada ao meio. O problema ainda mais se agrava não somente pela monocultura da cana de açúcar, como pela impossibilidade de em tal atividade estabelecer a divisão e redistribuição da propriedade, a não ser com incalculáveis prejuizos da produção. A expropriação, em país com abundância de terras, máxime em fase de desenvolvimento industrial, necessitando assim maior capacidade de importar, não induz a uma divisão de propriedades. Esta só se compreenderia pela formação de sistema cooperativista de trabalho e em conseqüência a diversificação da produção agropecuária e de modo intensivo. Contudo, na atividade agrícola dos empreendimentos maiores é que encontramos a possibilidade de maior capitalização, condição especifica da Produtividade. Esta inclusive liberta braços para a indústria e permite a captura de novos proprietários rurais. No primeiro caso, o surto industrial da região ainda é bastante incipiente; quanto ao segundo, a Colonização permitirá tão-sòmente a formação de futuros proprietários rurais como tipo cooperativista ou coletivo de trabalho, forma que facilite a assistência sob tôdas as formas.

Existe contudo um óbice a considerar; a tradição de fixação ao local, mesmo nas precárias condições de vida. No entanto, a região por suas condições sociais necessita com prioridade da atenção do Govêrno. Dentro da ação psicológica social encontra- 
mos meios satisfatórios para conseguir a fixação em outros sítios. Aconselhamos a seguinte conduta:

1. Assistentes sociais colherão dados detalhados sôbre condições de vida locais e a predisposição para a formação de novos proprietários rurais em região de nova colonização, não muito distante daquela em foco. Sendo o resultado examinado e considerado negativo, selecionam-se elementos favoráveis e inicia-se com êles a nova Colonização. Uma região a considerar seria aquela do agreste do Estado do Piaui. Constitui esta unidade federativa a que demonstra menor indice de renda "per capita". Mesmo que a Colonização seja iniciada com menos de mil familias, quantidade que consideramos a mais favorável para o custo de uma iniciativa em condições hígidas, as comunicações daqueles pioneiros aos que ficaram forçarão a adesão que completará o número acima mencionado. Contudo, é preciso que as condições da nova vida sejam capazes de sugerit a nova atitude.

2. No empreendimento poderão engajar-se ainda elementos captados na zona do Cariri cujas condições especiais exigem procedimentos diferentes, que passamos a expor:

3. A zona do Cariri, no Estado do Ceará, é constituída de terra valorizada e explora a monocultura da cana de açúcar. As terras estão, outrossim, muito fragmentadas. O combate ao "minifúndic." é uma necessidade social tão marcante quanto ao latifúndio. A terra valorizada exige a atividade intensiva agropecuária, preferindo-se o sistema granjeiro. Assim, uma politica de colonização exige uma ação sugestiva, tanto para aquisição de terras para ampliação das glebas locais, como ao oferecimento de vantagens ao deslocamento de uma parte dos proprietários locais. Chama-se operação de "consolidação" (França) ou "concentração". O nôvo núcleo colonial pelas sugestões oferecidas poderá conseguir o deslocamento e as vantagens creditícias poderão ampliar o tamanho das propriedades locais. Por outro lado, ações sugestivas especiais conseguirão implantar o sistema cooperativista de exploração granjeira da zona do Cariri. Através da Cooperativa e assistência global poderá estender-se com facilidade a todos os agricultores. A extensão rural tratará de conseguir a racionalização econômica da administração das propriedades assim como conseguir pela pequena indústria doméstica e rural o aproveitamento dos excedentes, caso haja dificuldades de consumo imediato ou a curto prazo. O sistema cooperativista definirá por várias direções a sua atuação, como veremos adiante. Preciso acentuar aqui que a Associação Brasileira de Crédito e Assistência Rural conseguiu reembôlso de $98 \%$ das quantias emprestadas no último ano e em certos casos, aumentar quatro a cinco vêzes a 
renda dos agricultores assistidos por ela. A própria Cooperativa, nas condições educacionais precárias em que se encontra o nosso meio rural, necessita de decidido e concreto apoio, pelo menos até consolidar-se. Os agricultores não compreendem a finalidade de segurança em relação a êles da atuação da Cooperativa e, por manobras sugestivas e suspeitas de intermediários, abandonam o órgão.

4. Mantemos ainda extensos espaços vazios entregues aos mais rudimentares hábitos de vida. Vigoram os métodos ilegais de viver e vencem quase sempre os marginais sociais, lançando mão de métodos criminosos. Ora, justamente as longínquas fronteiras do norte e nordeste do país estão entregues à irresponsabilidade cívica de tal organismo de segurança da Pátria.

As vias fluviais exerceram e ainda exercem um importante papel nas comunicações e no desenvolvimento econômico de numerosas e grandes Nações. Possuimos no norte e nordeste do país uma rêde fluvial pràticamente ineficaz e inaproveitada no que respeita a possibilidades imensas na distribuição de produção e na difusão cultural. Por motivos politicos de elevado alcance para a mobilização de potencial nacional encontramos o imperativo de serem estabelecidos núcleos de colonização nas regiões fronteiriças por onde penetram no território nacional os rios da bacia amazônica. O rio Negro nascendo no planalto colombiano de Popayan com o nome de Guiânia tem um curso de 1.370 quilô. metros em territôrio brasileiro, do total de 1.700 de sua extensão. O rio Japurá, também nascendo na Colômbia, tem um curso de $2.50 \mathrm{C}$ quilômetros. O rio Solimões, com o nome de Tungurágua e Marañon no Peru, denomina-se Amazonas quando recebe seus afluentes Javari e Negro.

Não poderemos aguardar que o progresso e a civilização possam atingir aquelas paragens na sua evolução normal. Quanto outros motivos não tornassem evidente o imperativo de colonização, as determinações da Segurança Nacional o exigem. Contudo, o estágio educacional em que nos encontramos, influenciando sobremodo a esfera politica, nos conduz a aconselhar una outra forma de colonização para aquelas regiões. A exemplo dos batalhões rodoviários e ferroviários, a direção dos trabalhos e o funcionamento da organização, até atingir ao ponto exato em que poderá formar uma unidade político-administrativa, deverão estar a cargo da Marinha de Guerra. Temos tido provas cabais da existência de pioneiros e patriotas de elevado senso. Com êles evoluiu a Colônia Nacional de Ceres em Goiás, hoje municipio independente. A estrada Belém-Brasilia é obra típica de pioneirismo e patriotismo de seus construtores. As condições do meio exigem uma ordem e disciplina capazes de vencer as influências 
politico-partidárias regionais e os procedimentos sociais marginais mantendo um minimo de moral social. Tais colonizações serão conduzidas por batalhões anfibios. As vias fluviais terão importância inconteste no empreendimento.

5. No sul do país, especialmente na zona da serra do Estado do Rio Grande do Sul e no vale do Rio Itajaí em Santa Catarina impõe-se a correção dos minifúndios pelo sistema acima mencionado quanto ao vale do Cariri. Contudo, o norte e o nordeste constituem as regióes que necessitam da maior premência de ação.

6. Uma região, na qual seriam indicados os sistemas granjeiro e cooperativista de trabalho agrícola, é litoral sul do Estado de São Paulo. Um dos objetivos do planejamento da produção agrícola é o fácil escoamento e o consumo. Aquela região pode estar dentro da classificação de subdesenvolvida, no entanto as terras estão valorizadas pela proximidade de estradas-tronco e cidades populosas. Acreditamos inconsistente a orientação atual de atividades agrícola extensiva e de ciclos longos como o seringal e o cacaueiro. Quando construirem as estradas de interpenetração, será constatada a conveniência da atividade agricola de ciclos curtos e intensiva. Impõe-se o sistema granjeiro cuja produção mais valorizada por área permitirá atender a um número maior de agricultores com elevação razoável do nível de vida. Nesta base o empreendimento poderá ser financiado pela Carteira de Colonização do Banco do Brasil. Quando o sistema de trabalho fôr dirigido para a instalação da agropecuária intensiva, os prazos e os juros poderão ser menos inflexiveis. Via de regra, as regiões de minifúndios são justamente aquelas próximas das facilidades de escoamento e de consumo, onde impera a sugestão do trabalho agropecuário intensivo.

7. No volume excepcional do sistema de trabalho agrícola predatório e nômade, o extensionismo agrícola poderá selecionar elementos que constituirão os novos proprietários dos núcleos de colonização. Por outro lado, na influência quanto à difusão cultural dos centros de colonização, no que denominamos "o efeito germinativo" educacional e econômico, serão beneficiados os que trabalham a terra inadequadamente como alternativa de subsistência. A expansão do trabalho da Associação Brasileira de Crédito e Assistência Rural ( $A B C A R$ ) e convênios com os núcleos de colonização serão um auxilio apreciável à racionalização do trabalho agrícola. 
V

ESQUEMA PARA O PLANEJAMENTO DAS COLONIZAÇÕES

A) Em primeiro lugar será estabelecido um plano da Política de Colonização. De acôrdo com a presente exposição já poderemos verificar sob que aspectos e de que modo as colonizações deverão atuar para corrigir os fatôres negativos da conjuntura. Indiscutivelmente o norte e o nordeste enquadram-se na linha de prinridade para início do programa colonizador. Um critério seria a avaliação da "renda per capita", no trabalho agrícola em tal ou qual Estado e região. Já exemplificamos com o Estado do Piauí. Por outro lado seria a referência para um programa o aproveitamento adequado das terras próximas e centros urbanos. Mesmo aqui sugerimos a prioridade para as regiões acima mencionadas onde existe produção deficiente de gêneros e produtos granjeiros frente ao consumo local. Realmente os produtos hortícula e granjeiro devem ser produzidos no distrito e os cereais básicos de alimentação, na região geo-econômica.

B) Uma Comissão heterogênea, com engenheiro, agronômo, higienista, economista, biologista de solos, geógrafo etc., com seus recursos deverá proceder ao "reconhecimento" das terras oferecidas para localização da Colônia. Com as modernas aquisições da Tecnologia, sòmente os condições físicas serão consideradas preponderantes para a escolha. Nos outros vigorarão as possibilidades de custo das obras iniciais corretivas: dragagens, distâncias de aguadas, condições ecológicas, rápido inventário do "status social" local, população, tendências, tradições etc. Êste ponto de partida dará condições especiais para o planejamento. Os dados históricos e legais da propriedade a ser utilizada dão maior segurança aos futuros procedimentos ligados ao planejamento. 'Terminado o rápido reconhecimento e a fase jurídica, começarão os trabalhos iniciais que darão lugar ao planejamento.

1? FASE

A) Levantamento topográfico - Mapa

B) Demarcação da futura área urbana e sede dos trabalhos administrativos. Loteamento com demarcação dos lotes periurbanos de agropecuária intensiva, dos lotes e do potreiro cooperativo ou condominio. Traçado das vias de tráfico, nos limites extremos da área urbana e da via principal de trânsito interno.

Área favorável: 100.000 hectares. 
Distribuição:

$20 \%$ minimo para silvicultura.

$20 \mathrm{Hs}$. lotes de agropecuária intensiva.

$50 \mathrm{Hs}$. tamanho dos lotes.

(O tamanho dos lotes deve ter caracteristicas ecológicas, variando segundo as possibilidades agrícolas de cada um).

Área urbana

Potreiro: aproximadamente 1.000 ha. sendo mais aconselhável mais de um potreiro mesmo com áreas inferiores. Com 200 ha., e dispersas pela Colonização facilitará a sua utilização.

Divisão das áreas de loteamento em núcleos para exploração, destinando-se a cada um os elementos necessários para trabalho racional e para o sistema assistencial.

Cada núcleo terá:

a) casa de lavoura - assistência técnica, fornecimento de sementes, adubos, inseticidas, etc;

b) escola primária;

c) pôsto de saúde.

Assim, pois, a grande área de colonização será explorada por ztapas sucessivas formando núcleos sociais gozando de certa independência de funcionamento.

C) Instalação dos Serviços iniciais

1. Ambiente social dos pioneiros:

a) moradias;

b) alimentação

- Atividade agropecuária;

- Depósitos e armazéns;

- Material de trabalho.

2. Assistência social:

- Serviços médicos;

- Hospital; $\left({ }^{*}\right)$

- Centro sócio-educativo; $\left({ }^{\star *}\right)$

- Pôsto de saúde. $\left(^{\star \star \star}\right)$

(1) Sempre que possivel as instalaçôes devem ser de caráter definitivo, planejadas no sentido de progressão e de ampliação.

$\left(^{*}\right)$ O Hospital já deve obedecer a um plano definitivo.

$(* \star)$ O Centro Sócio-Educativo deverá ser inciado pelas dependências de cinema educativo, saláo de conferências ou auditório. As atividades serão iniciadas com os elementos pioneiros.

$(\star \star \star)$ O Pôsto de Saúde, já será definitivo e como tal destinado ao Núcleo Urbano. 
3. Inventário do solo do Núcleo inicial a ser trabalhado. Será aconselhável o loteamento concomitante de uma área de agropecuária intensiva e outra correspondente de Colonização que constituiram o Núcleo «A».

Assim, a produção seria iniciada na 1? fase, o que serviria para satisfação de necessidades dos pioneiros.

4. Início da construção de obras de infra-estrutura Social e Econômica:

a) água e distribuição;

b) usina hidrelétrica;

c) serraria;

d) olaria;

e) hospital, pôsto de saúde, centro sócio-educativo, cinema, campos de desportos. etc. $\left({ }^{*}\right)$

f) oficina mecânica.

$\mathrm{E}^{\prime}$ preciso ter em vista que a semente industrial deverá estar no pensamento do planejador. O inventário do solo acima mencionado já demonstra o interêsse pelas matérias-primas locais

2 FASE

Continuação das obras de infra-estrutura, abertura das estradas Tronco e de interpretação. Abertura de Novos Núcleos de Colônias -- " $A$ ", " $B$ ", " $C$ " etc., sempre completados pelos serviços assistenciais próprios. (Escolas, Postos de Saúde, Casas da Lavoura, etc.).

Nota: Cada colônia terá caracteristicas semelhantes ao Centro Urbano. Assim, a Escola ou Escolas, Pôsto de Saúde, Casa da Lavoura serão concentrados em local que facilite o acesso ao maior número de colonos, se possivel em áreas circunvizinhas (praça). Evidentemente o potreiro terá localização adequada.

\section{FASE}

Expansão dos trabalhos da fase anterior completando-se o Centro Urbano e ligando-se as diversas colônias ao mesmo por estradas com tráfego permanente. létrica.

Se possivel a substituição da energia termelétrica pela hidre-

Instalação das cooperativas de consumo e de distribuição. Instalação das sociedades assistenciais - ensino e saúde.

1. Associação de Assistência Hospitalar:

a) sócios;

b) doações e donativos;

(*) Já assinalamos acima. 
c) convénios,

d) subvenções.

2. Associações educacionais e culturais:

a) sócios;

b) doações e donativos;

c) convênios;

d) subvenções.

Cs serviços assistenciais deverão ser custeados pela sociedade, "sendo dada a cada qual segundo suas necessidades e cada qual de acôrdo com suas possibilidades", o que constará prèviamente dos contratos de venda dos lotes.

Funcionamento dos órgãos de coordenação assistencial

1. Hospital Rural: tal-Base;

a) coordenação e convênios com Hospital Distrital e Hospi-

b) coordenação com Pôsto de Saúde;

c) coordenação com o Serviço Correspondente do Centro Sócio-Educativo;

d) coordenação com sociedades culturais.

2. Centro Sócio-Educativo:

a) coordenação com as escolas primárias;

b) coordenação com centros educacionais e culturais de outras regiões e centros mais evoluidos. Intercâmbio educacional e cultural; cação, etc.;

c) convênios e acôrdos com Ministérios, Secretarias de Edu-

3. Pôsto Agricola e Fazenda Experimental:

a) plano de divulgação de métodos agrícolas;

b) coordenação com outros postos agrícolas, fazendas experimentais, escolas de agricultura, institutos agronômicos;

c) plano de florestamento. Seleção de essências adequadas à ecologia local e conformação física dos terrenos;

d) seleção de sementes e mudas;

e) ensino de indústria rural;

f) idem mecanização;

g) convênio com o Centro Sócio-Educativo para ensino prático agrícola e formação de clubes agrícolas. Florestamento e reflorestamento. Combate à erosão do solo. Cursos de orientação para professôres primários;

h) extensão rural. 
A Casa da Lavoura, poderá funcionar sob forma cooperativista, correspondendo assim a um serviço assistencial.

Dentro de certos dispositivos regulamentares as associações e sociedades acima descritas funcionarão sob a forma de sociedade de economia mista e administradas pelos próprios interessados.

4 FASE

Franco desenvolvimento da Colonização.

Início das amortizações da venda dos lotes.

Instalação da indústria de beneficiamento.

Terminados os periodos de "carência" podendo começar a expedição de títulos de propriedade.

Transformação dos serviços públicos em sociedades privadas com difusão do capital invertido.

Ampliação e pavimentação das vias de comunicações.

Ampliação do campo de aviação.

\section{CERTOS DETALHES TÉCNICOS}

por dia.

Cada familia de 5 pessoas necessita de $1.000 \mathrm{~m}^{3}$ de água

Cada KWH inicial (Diesel) custará $\mathrm{Cr} \$ 5.00$ (Cr\$1958).

Cada KWH instalado custará Cr\$20.000,00 ( $\mathrm{Cr} \$ 1958)$.

Uma usina hidrelétrica de $5.000 \mathrm{KW}$ custará ............ Cr $\$ 100.000 .000,00$.

$A$ não serem os investimentos de infra-estrutura social $e$ econômica descritos acima, tôda a marcha da Colonização poderá ser planejada em núcleos independentes. O financiamento parcelado atenderá as etapas anuais de infra-estrutura a serem completadas em 4 a 5 fases e à formação de Núcleos de Colônia dispondo de certa autonomia funcional.

Conforme as condições iniciais de obtenção de terras, de suas condições intrínsecas e extrínsecas, os financiamentos deverão variar em suas cotas. O Plano Geral custará .......... $\mathrm{Cr} \$ 1.500 .000 .000,00$ provàvelmente assim distribuidos:

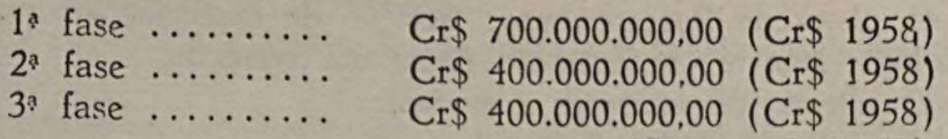

(Agôsto de 1959).

CONSTITUIÇ̃̃O E FINALIDADES DE UM CENTRO SÓCIO-EDUCATIVO gica;

1. Conselho educacional e setor de documentação pedagó-

2. Comissão de Administração do Fundo Financeiro; 
3. Educação experimental - Psicologia educacional;

4. Aperfeiçoamento do corpo docente local ou regional com o regime de internato;

5. Assistência social - Cadastro. Serviço de Coordenação;

6. Atividades vocacionais práticas - coordenação de competições culturais, civicas, desportivas, artísticas, profissionais e outras habilidades, funcionando com êste objetivo as suas instalações didáticas - desenho, impressão, oficinas, laboratórios, cinemas, fotografias, etc.; $\left({ }^{\star \star}\right)$

7. Preparação para as carreiras técnico-profissionais de grau médio e ligação com o $1^{\circ}$ ciclo de grau médio;

8. Biblioteca, mapoteca, e bibliografia; alunos;

9. Atividades sociais, intercâmbio entre professôres, pais e

10. Escotismo e bandeirantismo;

O Conselho Educacional e o Setor de Documentação pedagógica.

cuidarão de:

1. Pesquisas pedagógicas e aperfeiçoamento do método de ensino, confronto de experiências brasileiras e estrangeiras; novas pesquisas de educação;

2. Ajuda e orientação dos professôres em seus estudos, preparação de programas de trabalho do Centro, informações e cooperação intelectual e cultural entre professôres;

3. Informações a pais sôbre escolas, carreiras, profissões e vocações;

4. Assessoria técnica, educacional e cultural dos professôres;

5. Coordenação e relações educacionais e culturais com outros setores congêneres do país e do estrangeiro;

A gratuidade será banida das atividades da Colonização salvo em assuntos de excepcional interêsse da coletividade e do país.

Assim, o fornecimento de mudas de essências florestais será gratuita. A medicina preventiva, profilaxia e trabalhos de engenharia sanitária, medicina pré-natal e puericultura constituirão obrigação de Superintendência da Colonização. Outros setores estudados poderão enquadrar-se na mesma linha de conduta.

(**) As instalações técnicas do Centro constituirão material técnico de seleçăo vocacional espontânea, servindo os alunos como estagiários. Estes serão selecionados entre as escolas primárias pertencentes à constelação do Centro e através das competições referidas no item 6 .

O Centro está organizado com o objetivo de sanar os fatôres negativos da escola primária brasileira. 
Expansão continuada, iniciando-se com 1.000 familias e 100.000 hectares ..... área florestada de 20 a $25 \%$.

Prazo de 6 anos ..... formação progressiva de novas unidades politicas.

\section{ENSAIO DE DISTRIBUIÇAO DE VERBAS (Cr\$ 1958)}

\section{Fase \\ I - estudos PRELIMINARES}

a) Levantamentos topográficos;

Cr\$

b) Obras de engenharia - Demarcações;

c) Florestamento;

d) Loteamento da área "A" - conjugada;

e) Acampamentos;

t) Administração.

Prazo: 4 meses

120.000 .000 .00

II - OBRAS DE INFRA-ESTRUTURA (Cr\$ 1958)

1. Etapa
a) Usina Hidrelétrica ...........
Cr\$
b) Agua e esgotos. Rêde distri-
$50.000 .000,00$
$\mathrm{Cr} \$$
buidora de água da área " $\mathrm{A}$ "
$30.000 .000,00$
$20.000 .000,00$
c) Núcleo sócio educativo .......
$20.000 .000,00$
d) Casa Central da Lavoura .... mento " $\mathrm{A}$ " ........
f) Olaria $\ldots \ldots \ldots \ldots \ldots \ldots \ldots \ldots \ldots \ldots \ldots \ldots$

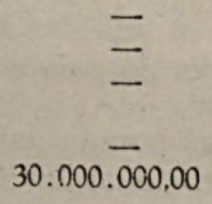
h) Escolas Primárias do Lotea- mento "A"
$100.000 .000,00$
$60.000 .000,00$
$40.000 .000,00$
$40.000 .000,00$
$5.000 .000,00$
$5.000 .000,00$
$12.000 .000,00$

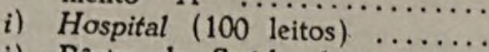
j) Pôsto de Saúde da zona ur- bana.$\ldots \ldots \ldots \ldots \ldots \ldots \ldots \ldots \ldots \ldots \ldots$
k) Pôsto de Saúde do Lotea- mento " $A$ " ...............
$1.500 .000,00$ $60.000 .000,00$
$15.000 .000,00$
$5.000 .000,00$

Total

Prazo: 22 meses

\section{2* Etapa}

a) Casas da zona urbana ......

b) Casa de Superintendência (fu-

Cr\$ tura sede da Prefeitura e Secretarias)

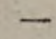

$9.000 .000,00$

$50.000 .000,00$ 
c) Casas da zona rural (com dependência de trabalho - benfeitorias $\ldots \ldots \ldots \ldots \ldots \ldots \ldots \ldots$.

d) Estradas de penetração - Es tradas internas, obras de engenharia Loteamentos

$$
\begin{gathered}
\text { III - COLONIZAÇÃo TIPO "A" } \\
\text { 2" Fase }
\end{gathered}
$$

1. Levantamentos topográficos

2. Obras de engenharia

3. Florestamento

4. Loteamento de novas áreas

"B", "C". "D" etc.

5. Acampamentos

6. Administração

7. Trabalhos Assistenciais

OBRAS DE INFRA-FSTRUTURA

1. Etapa

Total

Cr\$ Cr\$
a) Usina Hidrelétrica ...........
$20.000 .000,00$
$100.000 .000,00$
b) Água e esgotos. Rêde de dis- tribuiçã̃o de água $. . \ldots \ldots \ldots . .$.
c) Núcleo Sócio-Educativo ..... $15.000 .000,00$
d) Casa Central da Lavoura ... 15.000.000,00
$40.000 .000,00$
e) Hospital $30.000 .000,00$

\section{Etapa}

a) Casa da zona rural ............... (300)

b) Casas da zona urbana $\ldots \ldots \ldots \ldots \ldots \ldots$ (20)

\section{Cr\$}

$54.000 .000,00$ $3.800 .000,00$

c) Estradą de penetração e de intercomunicação

Obras de engenharia:

$102.200 .000,00$

Loteamentos

Prazo: 19 meses

Total da $2 *$ fase 


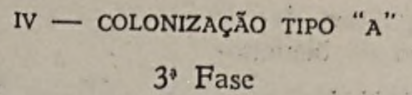

1. Levantamentos topográficos

$\mathrm{Cr} \$$

2. Obras de engenharia

3. Florestamento

4. Loteamentos

5. Acampamentos

6. Administração

7. Trabalhos assistenciais

$\left({ }^{\star}\right)$

$200.000 .000,00$

OBRAS DE INFRA-ESTRUTURA

1. Etapa

a) Usina Hidrelétrica

Cr\$

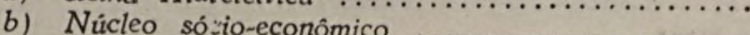

$30.000 .000,00$

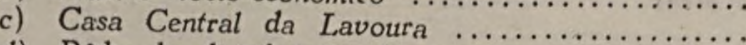

d) Rêde de distribuição de água

\section{Etapa}

a) Casa na zona rutal

$\mathrm{Cr} \$$

b) Estradas de penetração e de intercomunicação ..

$145.000 .000,00$

Prazo: 19 meses

Total da $3^{*}$ fase

(*) Construção dos Postos de Saúde, Casas de Lavoura e Escolas Primárias. 


\section{COLONIZAGÁO TIPO ${ }^{\circ}$}

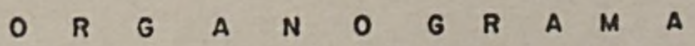

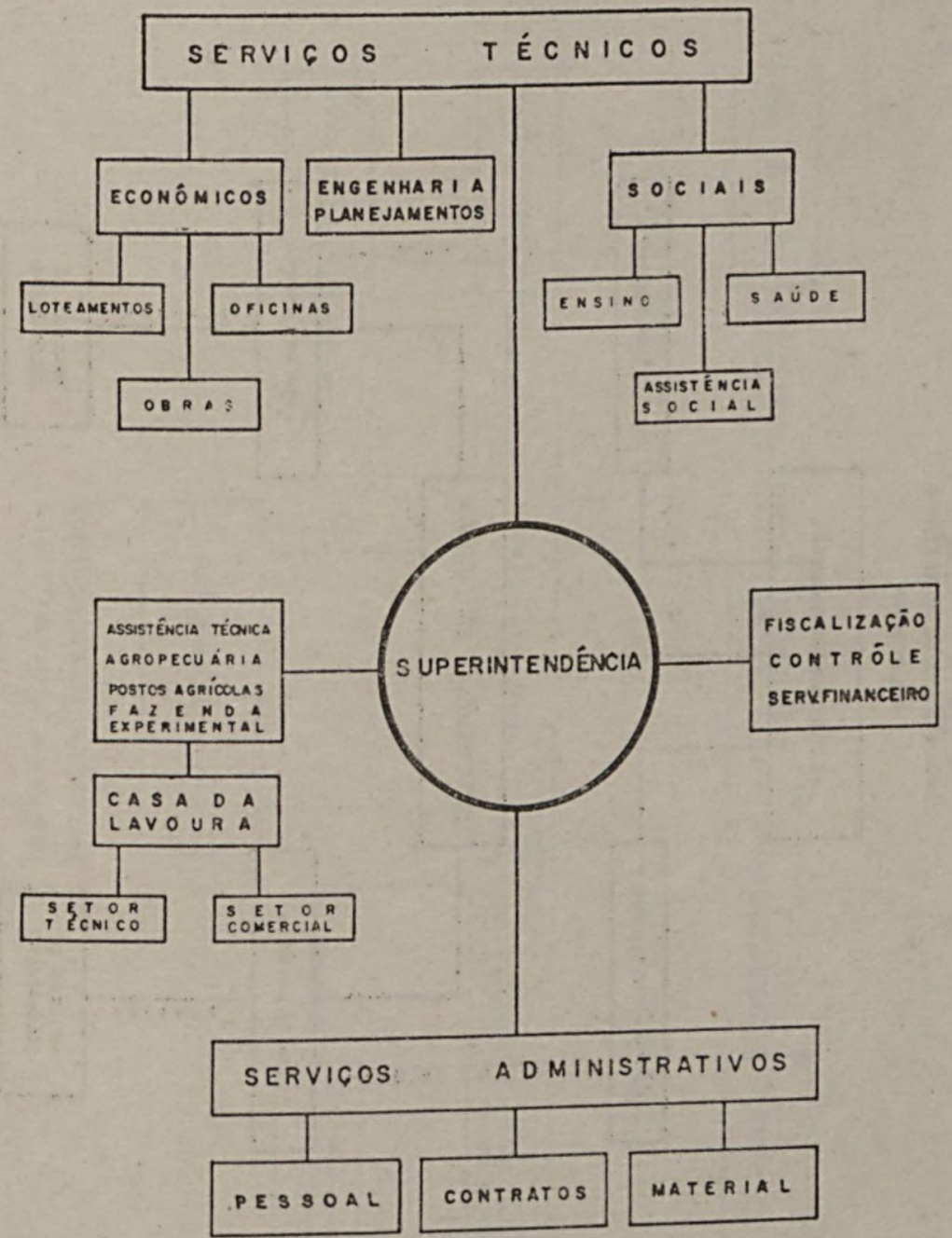

JOSE $\dot{E}$ LMEIDA RIOS

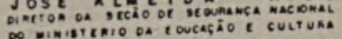




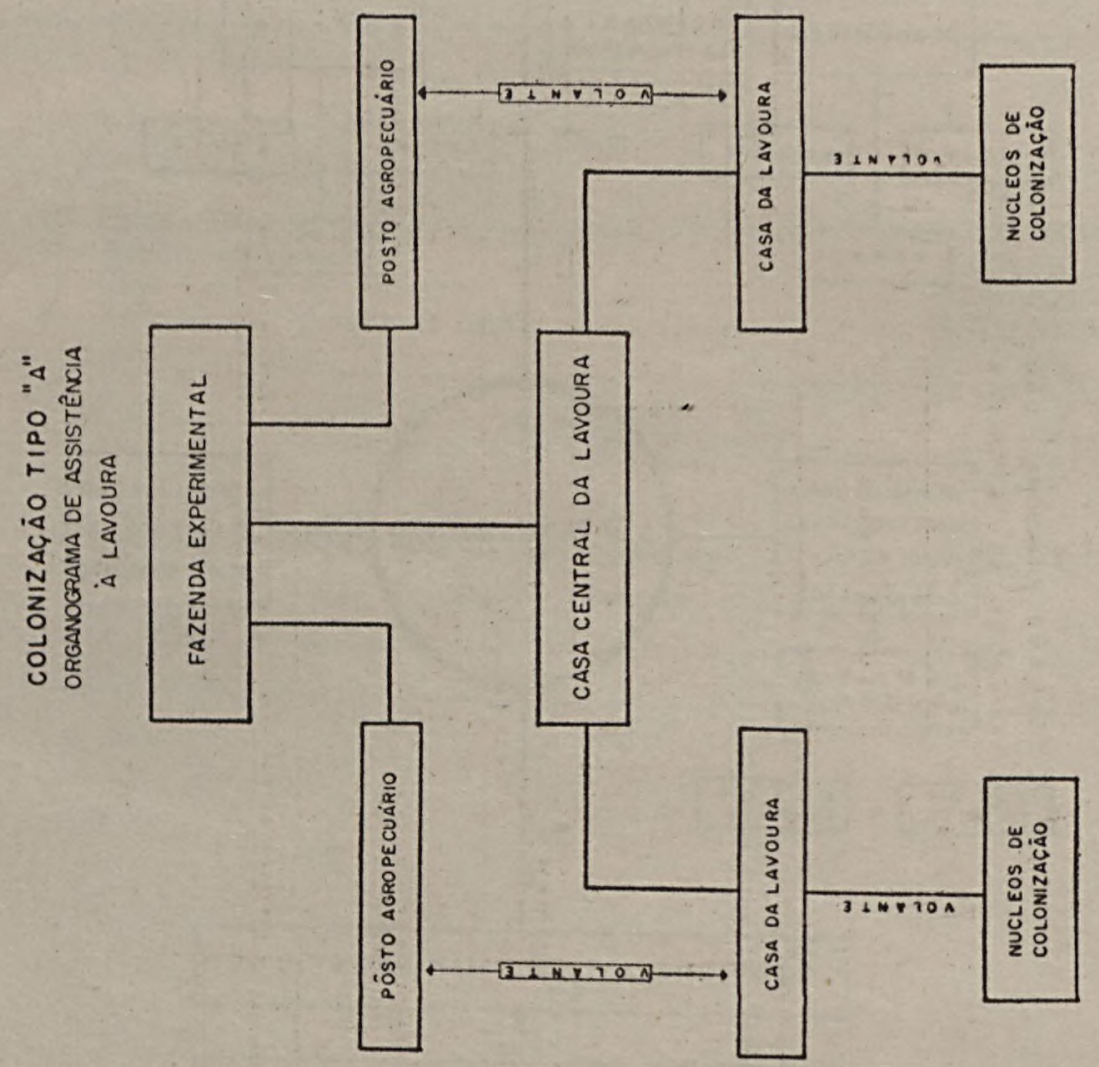







ESTADO DO PIAUI

REGILOO ONDE PODERIA SER ESCOL HIDA A $\triangle R E A$ PE

COLONIZACCAO TIPO "A"
(TERRAS DEVOLUTAS ESTADUAIS?)

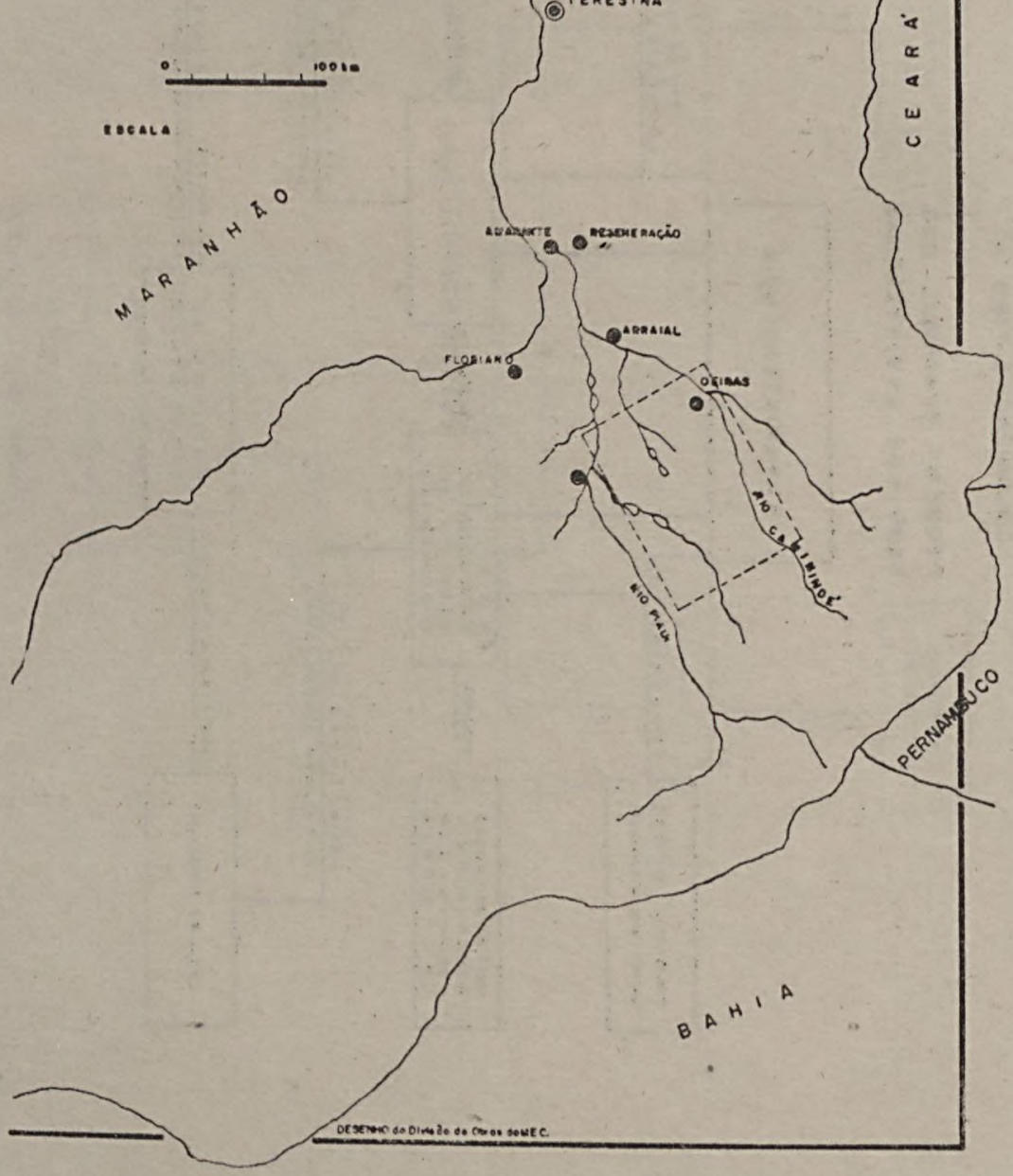

